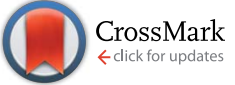

Cite this: Chem. Sci., 2015, 6, 1394

Received 10th October 2014

Accepted 26th November 2014

DOI: $10.1039 / c 4 s c 03117 b$

www.rsc.org/chemicalscience

\section{Direct catalytic cross-coupling of alkenyllithium compounds $\dagger$}

\author{
Valentín Hornillos, Massimo Giannerini, Carlos Vila, Martín Fañanás-Mastral \\ and Ben L. Feringa*
}

A catalytic method for the direct cross-coupling of alkenyllithium reagents with aryl and alkenyl halides is described. The use of a catalyst comprising $\mathrm{Pd}_{2}(\mathrm{dba})_{3} /$ XPhos allows for the stereoselective preparation of a wide variety of substituted alkenes in high yields under mild conditions. In addition (1-ethoxyvinyl) lithium can be efficiently converted into substituted vinyl ethers which, after hydrolysis, give readily access to the corresponding methyl ketones in a one pot procedure.

\section{Introduction}

Palladium-catalysed cross-coupling of organometallic reagents with organic halides represents one of the most powerful methods for the construction of carbon-carbon bonds. ${ }^{1}$ Among these, reactions employing alkenylmetal reagents remain indispensable tools to access a broad range of highly substituted olefins and polyenes. ${ }^{2}$ With a variety of structurally diverse, functionalized organic halides available, the challenge of this transformation often remains the choice of the alkenyl nucleophile. $\operatorname{Tin}^{3}$ and boron ${ }^{4}$ reagents are frequently used for these coupling reactions. However, the high toxicity of organostannanes makes the Stille crosscoupling often less desirable. On the other hand, alkenyl boronic acids are prone to rapid protodeboronation or polymerization so requiring large excess of the coupling partner. Elegant solutions have been found via the conversion into more stable derivates such as boronic esters, MIDA boronates $^{5}$ and trifluoroborates. ${ }^{6}$ Organosilicon compounds feature high stability and low toxicity although the use of fluoride anion for the activation is generally needed. ${ }^{7}$ Nonetheless, non-fluoride activators have recently been introduced to enhance the utility of these compounds. ${ }^{8,2 d}$ Alkenyl reagents for the Negishi cross-coupling ( $\mathrm{Zn}, \mathrm{Al}$ and $\mathrm{Zr}$ ), have also been used in Pd-catalysed alkenylation reactions with a broad scope for the synthesis of dienes and polyenes. ${ }^{9}$ These alkenyl intermediates are routinely prepared by elementometalation ${ }^{9}$ from alkynes or transmetallation from the corresponding organolithium reagents, as is the case for boron, tin and silicon reagents. In contrast, the direct use of alkenyllithium compounds ${ }^{10}$ have, to the best of our

Stratingh Institute for Chemistry, University of Groningen, Nijenborgh 4, 9747 AG Groningen, The Netherlands. E-mail: b.l.feringa@rug.nl; Fax: +31 50363 4278; Tel: +31503634296

$\dagger$ Electronic supplementary information (ESI) available. See DOI: $10.1039 / \mathrm{c} 4 \mathrm{sc} 03117 \mathrm{~b}$ knowledge, not been reported in Pd-catalysed cross-coupling reactions. Alkenyllithium reagents are easily accessible by lithium-halogen exchange or via direct metallation of the corresponding olefins without requiring purification prior to use. ${ }^{11}$ Their high reactivity has largely prohibited the use of these reagents in cross-coupling reactions due to the lack of selectivity. Pioneering studies by Murahashi and co-workers on the use of aryl and alkyllithium reagents in catalytic crosscoupling reactions revealed the limitations associated with their high reactivity. ${ }^{12,13}$ However, if controlled, this reactivity might be advantageous in facilitating the transmetallation with Pd allowing for milder reaction conditions which are beneficial to preserve the geometry of the alkene. In addition, their use would also drastically reduce the amount of byproducts generated with the light and non-toxic lithium halide being the only stoichiometric waste. Therefore, the development of a general method for the use of alkenyllithium reagents in catalytic cross-coupling reactions is highly desirable.

Recently, our group reported the direct palladium catalysed cross-coupling of alkyl and (hetero)aryl lithium reagents with aryl and alkenyl (pseudo)halides, providing high yields and selectivity. ${ }^{14,15}$ The choice of the proper combination of catalyst and reaction conditions allows for efficient transmetallation, prevents the notorious lithium halogen exchange and homocoupling reactions and gives rise to the corresponding cross-coupled products in high yields. However, the use of alkenyllithium reagents in this transformation remains elusive.

Herein, we report a palladium-based method for the direct catalytic cross-coupling of alkenyllithium reagents and organic halides to afford substituted alkenes in high yield and isomeric purity under mild conditions in short reaction times (Scheme 1). 


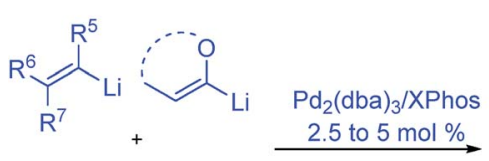

$\mathrm{R}^{1}-\mathrm{X}$

$\mathrm{X}=\mathrm{Cl}, \mathrm{Br}$

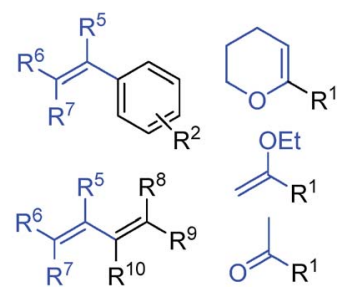

Scheme 1 Palladium catalysed cross-coupling of alkenyllithium reagents.

\section{Results and discussion}

Our investigation started with the reaction between (3-methylbut-2-en-2-yl)lithium, readily prepared from the corresponding bromide, and 4-methoxy-bromobenzene 1a, a reluctant arylbromide in many coupling reactions, ${ }^{16}$ in the presence of various Pd-based catalytic systems using toluene as solvent (Table 1).

The use of $\operatorname{Pd}\left[\mathrm{P}(t-\mathrm{Bu})_{3}\right]_{2}{ }^{17}$ (Table 1 , entry 1 ), a catalyst we previously disclosed to be highly successful for the crosscoupling of alkyllithium reagents with aryl bromides ${ }^{\mathbf{1 4 a}, \boldsymbol{d}}$ led to the desired product $\mathbf{2 a}$ but in the presence of a large amount of dehalogenated side product 3 . We then examined the use of Buchwald biaryl phosphine ligands ${ }^{18}$ in combination with $\mathrm{Pd}_{2}(\mathrm{dba})_{3}$ (2.5 mol\%). When ligands $\mathbf{L 1}$ and $\mathbf{L} 2$ were used, incomplete conversion was observed, along with homocoupling

Table 1 Screening of different Ligands

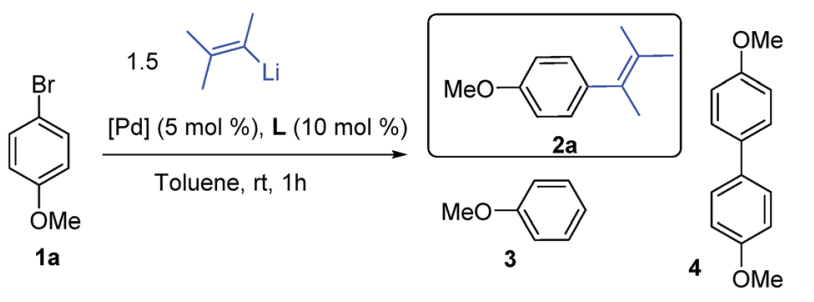<smiles>[R]c1cc([R])c(-c2ccccc2[R])c([R])c1</smiles>

L1: $\mathrm{X}=\mathrm{Cy}, \mathrm{R}^{1}=\mathrm{R}^{2}=\mathrm{OMe}, \mathrm{R}^{3}=\mathrm{H}$ L2: $X=\mathrm{Cy}, \mathrm{R}^{1}=\mathrm{R}^{2}=\mathrm{NMe}_{2}, \mathrm{R}^{3}=\mathrm{H}$ L3: $X=C y, R^{1}=R^{2}=R^{3}=/ P r$

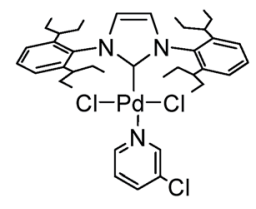

Pd-PEPPSI-IPent

\begin{tabular}{lllll}
\hline Entry $^{a}$ & {$[\mathrm{Pd}]$} & Ligand & Conv. (\%) & $\mathbf{2 a}: \mathbf{3}: \mathbf{4}^{b}$ \\
\hline 1 & $\mathrm{Pd}\left[\mathrm{P}(t-\mathrm{Bu})_{3}\right]_{2}$ & & Full & $44: 56: 0$ \\
2 & $\mathrm{Pd}_{2}(\mathrm{dba})_{3}$ & L1, SPhos & 46 & $83: 0: 17$ \\
3 & $\mathrm{Pd}_{2}(\mathrm{dba})_{3}$ & L2, CPhos & 38 & $87: 0: 13$ \\
4 & $\mathrm{Pd}_{2}(\mathrm{dba})_{3}$ & L3, XPhos & Full & $>99: 0: 0$ \\
5 & $\mathrm{Pd}$ PEPPSI-IPent & Full & $96: 0: 4$
\end{tabular}

${ }^{a}$ Conditions: (3-methylbut-2-en-2-yl)lithium (0.40 mmol, $0.6 \mathrm{M}$ in THF) was added to a solution of $1 \mathrm{a}(0.3 \mathrm{mmol})$ and catalyst in toluene $(1 \mathrm{~mL})$, $1 \mathrm{~h}$ addition time. ${ }^{b} 2 \mathrm{a}: 3: 4$ ratios determined by GC analysis. $\mathrm{dba}=$ dibenzylideneacetone. side product 4 (entries 2 and 3). To our delight, the use of XPhos L3 led to the cross-coupled product $2 \mathrm{a}$, in $1 \mathrm{~h}$ at r.t., with excellent selectivity (>99\%), avoiding dehalogenation and inhibiting the formation of the homocoupling product (entry 4). We also found that the air stable Pd-PEPPSI-IPent catalyst, introduced by Organ, ${ }^{19}$ displayed good selectivity although the presence of $4 \%$ of homocoupling was observed (entry 5).

With $\mathrm{Pd}_{2}(\mathrm{dba})_{3} / \mathrm{Xphos}$ as a highly efficient catalytic system, we set out to investigate the scope of this new reaction (Table $2)$ \% A wide variety of alkenes were readily lithiated via direct metallation or by halogen-lithium exchange as shown in Scheme 2 (see ESI $\dagger$ for details).

The catalytic system proved to be also highly efficient in the reaction of (3-methylbut-2-en-2-yl)lithium with 1-chloronaphthalene $\mathbf{1 b}$ at r.t. (see also ESI, Table $\mathrm{S} 1 \dagger$ ). The corresponding

Table 2 Pd-catalysed cross-coupling of alkenyllithium reagents with aryl and alkenyl halides ${ }^{a}$

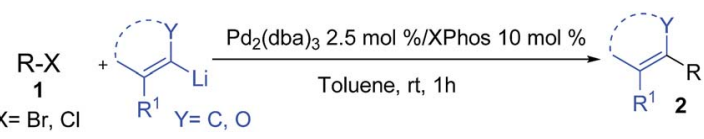
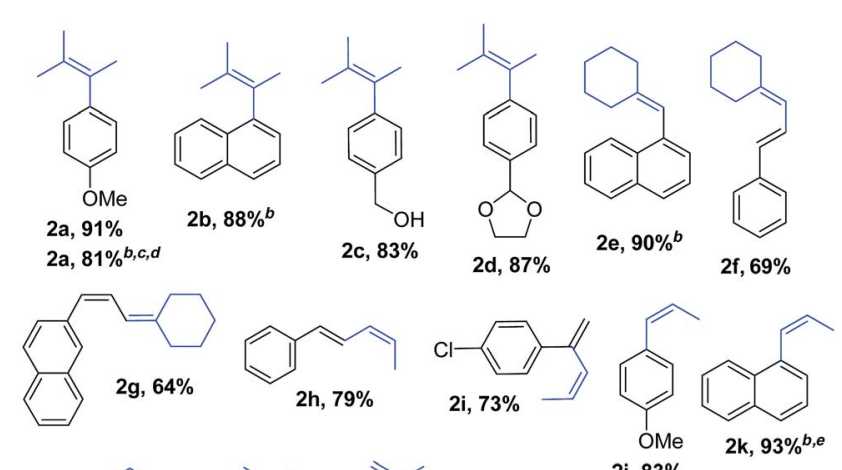
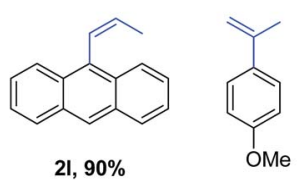

$21,90 \%$

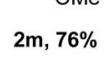

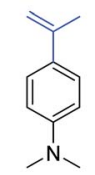

(15\%

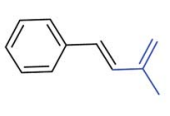

$20,81 \%$

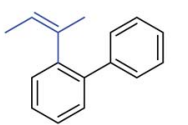

$2 p, 91 \%$<smiles>COc1ccc(/C=C/CO[SbH3])cc1/C=C/CCO</smiles>

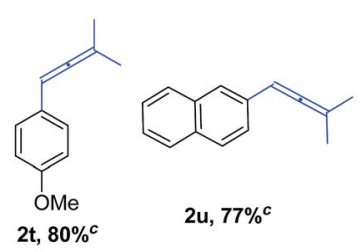<smiles>O=[W]c1ccc(C2=CCCCO2)cc1</smiles><smiles>COc1cccc(C2=CCCCO2)c1</smiles>

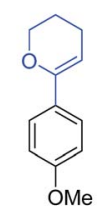

$2 w, 81 \%^{g} \quad 2 x, 76 \%^{g}$

${ }^{a}$ Conditions: RLi (1.3 equiv.) was added to a solution of organic bromide $(0.3 \mathrm{mmol})$ and catalyst in toluene, $1 \mathrm{~h}$ addition time unless otherwise noted. Selectivity $2: 3,4>90 \%$. Isolated yields after column chromatography. For limitations of the method see Table S3, Schemes $\mathrm{S} 2$ and S3. ${ }^{b} \mathrm{X}=\mathrm{Cl} .{ }^{c}$ The reaction was performed at $40{ }^{\circ} \mathrm{C} .{ }^{d} 3.5 \mathrm{~h}$ addition time. ${ }^{e}$ The reaction was performed at $35{ }^{\circ} \mathrm{C} .{ }^{f}$ After workup, product mixture was treated with TBAF to remove the silyl group prior to purification. ${ }^{g} 0.9 \mathrm{mmol}$ scale. Reaction performed at $60{ }^{\circ} \mathrm{C}$. 


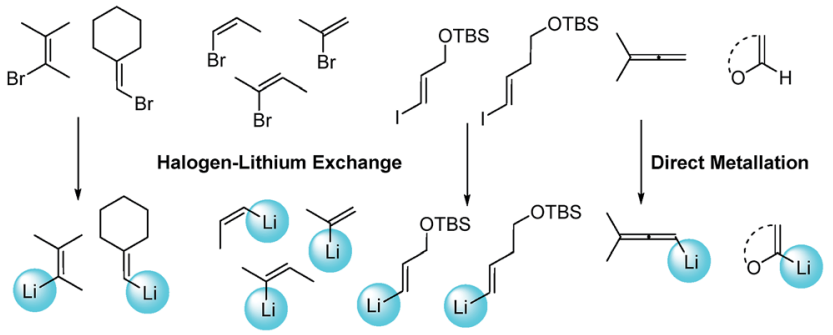

Scheme 2 Synthesis of alkenyllithium reagents.

tetrasubstituted alkene $\mathbf{2 b}$ was obtained in good yield with no trace of the 2-substituted regioisomer, indicating that benzyne intermediates via 1,2-elimination are not formed. To further explore the effectiveness of this catalytic systems we studied the more reluctant coupling partner 4-methoxy-chlorobenzene. ${ }^{14 b}$ Unfortunately, low conversion was found in the reaction at room temperature. However, the use of slightly higher temperatures $\left(40{ }^{\circ} \mathrm{C}\right)$ and longer addition times $(3.5 \mathrm{~h})$ of the organolithium reagent allowed full conversion with high selectivity (see ESI, Table S2 $\uparrow$ ). Substrate 1c, bearing an unprotected hydroxyl group, could also be coupled with this organolithium reagent (2.2 equiv.). The use of acetal-protected aldehyde 1d was also tolerated without cleavage of the protecting group. The cross-coupling of (cyclohexylidenemethyl)lithium and 1-chloronaphthalene proceeds efficiently giving alkene 2e in good yield. It is important to note that $(E)$ and $(Z)$ alkenyl bromides if and $\mathbf{1 g}$ reacted under the optimized conditions to give conjugated dienes $2 \mathbf{f}$ and $2 \mathrm{~g}$ in good yield and with no presence of Fritsh-Butlenberg-Wiechell type rearrangement side products. ${ }^{20}$ In addition, both $(E)$ and $(Z)$-olefins were coupled to form dienes $\mathbf{2 f}-\mathbf{2 h}$ with retention of stereochemistry. Illustrative is the use of (Z)-propenyllithium, obtained by treatment of $(Z)$-1-bromopropene with elemental lithium, which was smoothly coupled with retention of the (Z)-configuration, with a variety of alkenyl and aryl bromides providing the corresponding dienes $2 \mathbf{h}, 2 \mathbf{i}$ and alkenes $2 \mathbf{j}, 2 \mathbf{k}$ and $\mathbf{2 l}$ in good yields. Synthesis of diene $\mathbf{2 h}$ illustrates that both the alkenyl nucleophile and electrophile retain their geometrical configuration as confirmed by ${ }^{1} \mathrm{H}$ NMR. ${ }^{21}$ In addition, vinyl bromide $1 \mathrm{i}$ reacted chemoselectively, leaving the chloride intact and available for further functionalization. It is interesting to note that (Z)-propenyllithium compared with the more hindered (3-methylbut-2-en-2-yl)lithium, required higher temperature in the coupling with 1-chloronaphthalene. This result could be due to a faster reductive elimination taking place from the more strained $\mathrm{Pd}(\mathrm{II})$ intermediates. ${ }^{22}$ This result is in accordance with similar observation using less hindered 2-chloronaphthalene. (see ESI, Scheme S1†).

2-Propenyllithium underwent cross-coupling reaction with 4methoxy-bromobenzene and the more electron rich 4-bromo$N, N$-dimethylaniline providing styrenes $2 \mathbf{m}$ and $2 \mathbf{n}$ in good yield without the need to increase temperature or reaction time. Retention of the olefin configuration was also observed in the reaction of this organolithium reagent with $(E)$-bromostyrene $2 \mathbf{2}$. Moreover, a sterically hindered ortho-substituted arylbromide such as 2-bromo-1,1'-biphenyl $\mathbf{1 p}$ could be coupled in high yield and without loss of selectivity. Remarkably, alkenyllithium reagents bearing a protected alcohol functionality could also be used, providing the corresponding allylic TBS-protected alcohol 2q, allylic alcohol $2 \mathbf{r}$ and homoallylic alcohol $2 s$ in fair to good yields with retention of the $(E)$-configuration. Interestingly, compound $\mathbf{2 q}$ is an intermediate in the synthesis of (-)-cytoxazone, a Novel Cytokine Modulator Isolated from Streptomyces $\mathrm{sp.}^{23}$

We envisioned extension of this coupling to allenyllithium ${ }^{24}$ compounds, providing a synthesis of substituted allenes. ${ }^{25}$ Under the optimized reaction conditions the coupling between (3-methylbuta-1,2-dienyl)lithium, readily available by direct metallation of the corresponding allene, and both 4-methoxybromobenzene and 2-chloronaphthalene proceeded in good yields and high regioselectivity and with less than $5 \%$ of regioisomeric alkyne arising from 1,3-lithium shift of the organolithium reagent. ${ }^{26}$

Next the use of functionalized ( $\alpha$-alkoxyvinyl)lithium reagents in this new cross-coupling transformation was investigated. An illustrative example is the reaction of (3,4-dihydro$2 H$-pyran-6-yl)lithium, obtained by direct metallation of commercially available dihydropyran with $t$ BuLi. $^{27 a}$ To our delight, reaction with $p$-methyl- and $p$ - and $m$-methoxysubstituted bromoarenes provided compounds $2 \mathbf{v}, \mathbf{2 w}$ and $2 \mathrm{x}$ in high yields and excellent selectivity (Table 2). Due to the reduced reactivity of this organometallic reagent, a slightly higher temperature was required $\left(60{ }^{\circ} \mathrm{C}, 1 \mathrm{~h}\right)$. Nonetheless, established methods for the cross-coupling of glycal metal reagents require severe reaction conditions, long reaction times or they only were examined with the corresponding aryl iodides. ${ }^{27 b, c}$

Encouraged by these results, we studied other $\alpha$-alkoxyvinyl precursor such as the cheap and simple ethyl vinyl ether (Table 3 ). The use of the corresponding lithium reagent, readily obtained by direct lithiation, in the Pd-catalysed cross-coupling reaction could be used as a masked acetylating agent giving, after hydrolysis, the corresponding aryl methyl ketones. ${ }^{27 b, 28}$ This class of carbonyl derivates serves as versatile synthetic building blocks and are intermediates in the synthesis of drug candidates, fragrances and heterocycles. ${ }^{29}$ We performed this one pot transformation on larger scale $(6 \mathrm{mmol})$, employing 2.5 $\mathrm{mol} \%$ of catalyst to illustrate the synthetic utility of the method. As shown in Table 3, the method tolerates a variety of functional groups including acetals, ethers, amines alcohols and phenols. Electron rich substrates bearing amine, methyl and methoxy substituents underwent the expected coupling reaction at $40{ }^{\circ} \mathrm{C}$ in $2.5 \mathrm{~h}$ to give the corresponding ketones $\mathbf{6 a - 6 \mathbf { c }}$ in good yields. Remarkably, bromofluorene was successfully employed, despite the acidity of the benzylic protons $\left(\mathrm{p} K_{\mathrm{a}}=22\right)$. Although the formation of $\mathbf{6 e}$ demonstrates that hindered substrates are tolerated, we further validated this by coupling 9-bromoanthracene to give $\mathbf{5 f}$ in $78 \%$ yield. Facile multiple coupling is illustrated with the two fold acetylation of $4,4^{\prime}$-bis-bromobiphenyl, providing $6 \mathrm{~g}$ in $76 \%$ yield. $\beta$-Bromo-styrene was coupled in moderate yield, with retention of the configuration. Acetalprotected $p$-bromobenzaldehyde was also tolerated in the 
Table 3 Pd-catalysed cross-coupling of (1-ethoxyvinyl) lithium ${ }^{a}$

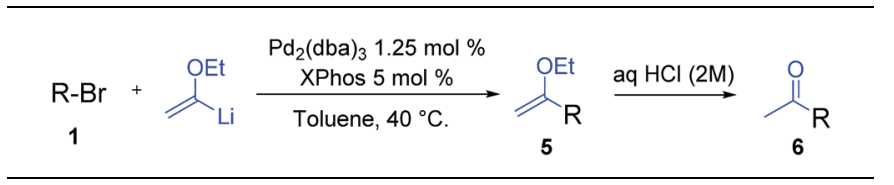

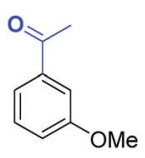

$6 a, 81 \%$

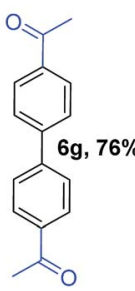

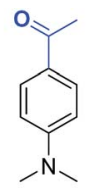

$6 b, 77 \%$<smiles>[13CH3][13CH3]</smiles>

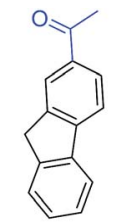

6d, $73 \%$

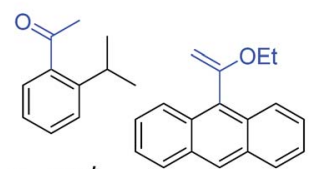

$5 f, 78 \%$

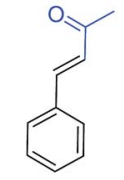

$6 \mathrm{~h}, 61 \%^{c}$

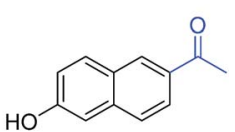

$6 k, 76 \%^{d}$

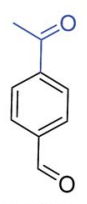

$6 i, 93 \%$

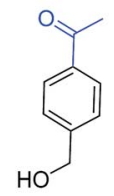

$6 \mathbf{j}, 67 \%^{d}$
${ }^{a}$ Conditions: $3.0-6.0 \mathrm{mmol}$ scale reaction. Aryl bromide (1 equiv.), (1ethoxyvinyl)lithium (1.5 equiv., $0.60 \mathrm{M}$ in THF). $2.5 \mathrm{~h}$ addition time. Toluene at $40{ }^{\circ} \mathrm{C}$. Selectivity $>90 \%$. Yield values refer to isolated yields after purification. ${ }^{b} 70 \%$ conversion. ${ }^{c} 80 \%$ selectivity. ${ }^{d}$ iPrMgCl $(1.0$ equiv., $2 \mathrm{M}$ in $\mathrm{Et}_{2} \mathrm{O}$ ) was added over 5 min prior to the organolithium.

reaction affording, after subsequent hydrolysis, 4-acetylbenzaldehyde $\mathbf{6 i}$ in excellent yield. Alcohols and phenols as $\mathrm{Mg}$ alkoxides are tolerated in this method to afford $\mathbf{6 j}$ and $\mathbf{6 k}$. It should be noted that same of the compounds obtained such as $\mathbf{6 a}, \mathbf{6 d}, \mathbf{6 e}, \mathbf{6} \mathbf{i}$, or $\mathbf{6 j}$ would be challenging to synthesize through standard Friedel-Crafts acylation chemistry. ${ }^{30}$

\section{Conclusions}

In summary, a fast and selective method has been developed for the Pd-catalysed alkenylation of aryl and alkenylhalides using organolithium reagents. This transformation leads to highly substituted alkenes under mild conditions and shows tolerance to various functional groups. Moreover, we describe the one pot synthesis of aryl methyl ketones involving coupling of lithiated alkenyl ethers.

\section{Acknowledgements}

The Netherlands Organization for Scientific Research (NWO-CW), the National Research School Catalysis (NRSC-C), the European Research Council (ERC advanced grant 227897 to BLF), the Royal Netherland Academy of Arts and Sciences (KNAW) and the Ministry of Education Culture and Science (Gravitation program 024.601035) are acknowledged for financial support. C.V. was supported by IntraEuropean Marie Curie fellowship (FP7-PEOPLE-2011-IEF300826).

\section{Notes and references}

$\ddagger$ Representative procedure: In a dry Schlenk flask $\operatorname{Pd}_{2}(\mathrm{dba})_{3}(2.5 \mathrm{~mol} \%)$ and XPhos (10 mol\%) were dissolved in toluene $(2 \mathrm{~mL} / 0.3 \mathrm{mmol}$ of substrate) and the solution was stirred under nitrogen atmosphere at room temperature for $5 \mathrm{~min}$. The substrate ( 1 equiv.) was added and the solution stirred at the indicated temperature. The corresponding lithium reagent solution (1.3 equiv., 0.6 or 0.68 $\mathrm{M}$, see ESI $\dagger$ for details) was slowly added over $1 \mathrm{~h}$ by the use of a syringe pump. After the addition was completed a saturated solution of aqueous $\mathrm{NH}_{4} \mathrm{Cl}$ was added and the mixture was extracted with $\mathrm{Et}_{2} \mathrm{O}$ or AcOEt. The organic phases were combined and dried with anhydrous $\mathrm{Na}_{2} \mathrm{SO}_{4}$. Evaporation of the solvent under reduced pressure afforded the crude product that was then purified by column chromatography.

1 (a) Metal-Catalysed Cross-Coupling Reactions, ed. A. de Meijere and F. Diederich, Wiley-VCH, Weinheim, 2nd edn, 2004; (b) Transition Metals for Organic Synthesis, ed. M. Beller and C. Bolm, Wiley-VCH, Weinheim, 2nd edn, 2004; (c) Handbook of Organopalladium Chemistry for Organic Synthesis, ed. E.-I. Negishi, Wiley-Interscience, New York, 2002; (d) Topics in Organometallic Chemistry: Palladium in Organic Synthesis, ed. J. Tsuji, Springer, New York, 2005; (e) C. C. C. Johansson Seechurn, M. O. Kitching, T. J. Colacot and V. Snieckus, Angew. Chem., Int. Ed., 2012, 51, 5062; (f) X.-F. Wu, P. Anbarasan, H. Neumann and M. Beller, Angew. Chem., Int. Ed., 2010, 49, 9047.

2 (a) Science of synthesis, ed. G. Molander, J. P. Wolfe and M. Larhed, Thieme, 2013; (b) S. E. Kelly,in Comprehensive Organic Synthesis, ed. B. M. Trost and I. Fleming, Pergamon, Oxford, 1991, pp. 729-817; (c) Preparation of Alkenes, ed. J. M. J. Williams, Oxford University, Oxford, 1996; (d) S. E. Denmark and C. R. Butler, Chem. Commun., 2009, 20.

3 (a) A. Suzuki, Angew. Chem., Int. Ed., 2011, 50, 6723; (b) L. Yin and J. Liebscher, Chem. Rev., 2007, 107, 133; (c) J. P. Corbet and G. Mignani, Chem. Rev., 2006, 106, 2651; (d) Boronic Acids, ed. D. G. Hall, Wiley-VCH, Weinheim, 2005; (e) N. E. Leadbeater, Chem. Commun., 2005, 2881.

4 (a) P. Espinet and A. M. Echavarren, Angew. Chem., Int. Ed., 2004, 43, 4704; (b) A. F. Littke, L. Schwartz and G. C. Fu, J. Am. Chem. Soc., 2002, 124, 6343; (c) J. K. Stille, Angew. Chem., Int. Ed., 1986, 25, 508.

5 (a) E. P. Gillis and M. D. Burke, J. Am. Chem. Soc., 2007, 129, 6716; (b) E. P. Gillis and M. D. Burke, Aldrichimica Acta, 2009, 42, 17; (c) E. M. Woerly, J. Roy and M. D. Burke, Nat. Chem., 2014, 6, 484.

6 (a) G. A. Molander, T. Barcellos and K. M. Traister, Org. Lett., 2013, 15, 3342; (b) E. Alacid and C. Nájera, J. Org. Chem., 2009, 74, 8191; (c) G. A. Molander and L. A. Felix, J. Org. Chem., 2005, 70, 3950; (d) G. A. Molander and C. R. Bernardi, J. Org. Chem., 2002, 67, 8424; (e) G. A. Molander and M. R. Rivero, Org. Lett., 2002, 4, 107.

7 (a) T. Hiyama and Y. Nakao, Chem. Soc. Rev., 2011, 40, 4893; (b) S. Bracegirdle and E. A. Anderson, Chem. Soc. Rev., 2010, 39, 4114.

8 (a) S. E. Denmark and C. S. Regens, Acc. Chem. Res., 2008, 41, 1486; (b) S. E. Denmark and C. S. Regens, Acc. Chem. Res., 2012, 45, 864 . 
9 (a) G. Wang, S. Mohan and E.-I. Negishi, Proc. Natl. Acad. Sci. U. S. A., 2011, 108, 11344; (b) E.-I. Negishi, Q. Hu, Z. Huang, M. Qian and G. Wang, Aldrichimica Acta, 2005, 38, 71; (c) R. Álvarez, B. Vaz, H. Gronemeyer and A. R. de Lera, Chem. Rev., 2014, 114, 1.

10 The use of organolithium and their subsequent transmetallation to softer organometallics to use in crosscoupling is well established: (a) E. J. Anctil and V. Snieckus, in Metal Catalysed Cross-Coupling Reactions, ed. A. de Meijere and F. Diederich, Wiley-VCH, Weinheim, 2004, vol. 1, pp. 761-813; (b) J. Board, J. L. Cosman, T. Rantanen, S. P. Singh and V. Snieckus, Platinum Met. Rev., 2013, 57, 234.

11 (a) Lithium Compounds in Organic Synthesis, ed. R. Luisi and V. Capriati, Wiley-VCH, Weinheim, 2014; (b) The Chemistry of Organolithium Compounds, ed. Z. Rappoport and I. Marek, Wiley-VCH, Weinheim, 2004; (c) V. Snieckus, Chem. Rev., 1990, 90, 879.

12 (a) S. Murahashi, M. Yamamura, K. Yanagisawa, N. Mita and K. Kondo, J. Org. Chem., 1979, 44, 2408; (b) S. Murahashi, J. Organomet. Chem., 2002, 653, 27.

13 For recent approaches to the indirect cross-coupling of organolithium reagents see: (a) A. B. Smith III, A. T. Hoye, D. Martinez-Solorio, W. Kim and R. Tong, J. Am. Chem. Soc., 2012, 51, 4533; (b) D. Martinez-Solorio, A. T. Hoye, M. H. Nguyen and A. B. Smith III, Org. Lett., 2013, 15, 2454; (c) M. H. Nguyen and A. B. Smith III, Org. Lett., 2014, 16, 2070, For an use of flow-chemistry technology for the Pd-catalysed cross-coupling with lithium reagents see: $(d)$ A. Nagaki, A. Kenmoku, Y. Moriwaki, A. Hayashi and J. Yoshida, Angew. Chem., Int. Ed., 2010, 49, 7543.

14 (a) M. Giannerini, M. Fañanás-Mastral and B. L. Feringa, Nat. Chem., 2013, 5, 667; (b) V. Hornillos, M. Giannerini, C. Vila, M. Fañanás-Mastral and B. L. Feringa, Org. Lett., 2013, 15, 5114; (c) M. Giannerini, V. Hornillos, C. Vila, M. Fañanás-Mastral and B. L. Feringa, Angew. Chem., Int. Ed., 2013, 52, 13329; (d) C. Vila, M. Giannerini, V. Hornillos, M. Fañanás-Mastral and B. L. Feringa, Chem. Sci., 2014, 5, 1361; (e) C. Vila, V. Hornillos, M. Giannerini, M. Fañanás-Mastral and B. L. Feringa, Chem.-Eur. J., 2014, 20, 13078.
15 For highlights of the use of organolithium reagents in crosscoupling, see: (a) V. Pace and R. Luisi, ChemCatChem, 2014, 6, 1516; (b) V. Capriati, F. M. Perna and A. Salomone, Dalton Trans., 2014, 43, 14204.

16 S. E. Denmark, R. C. Smith, W. T Tau and J. M. Muhuhi, J. Am. Chem. Soc., 2009, 131, 3104.

17 G. C. Fu, Acc. Chem. Res., 2008, 41, 1555.

18 R. Martin and S. L. Buchwald, Acc. Chem. Res., 2008, 41, 1461.

19 C. Valente, S. Calimsiz, K. H. Hoi, D. Mallik, M. Sayah and M. G. Organ, Angew. Chem., Int. Ed., 2012, 51, 3314.

20 H. Rezaei, S. Yamanoi, F. Chemla and J. F. Normant, Org. Lett., 2010, 2, 419.

21 The $E-Z$ geometry of both the alkenyllithium reagents and alkenyl halides is fully preserved; the product geometry was unequivocally established by ${ }^{1} \mathrm{H}$ NMR analysis and by comparison of the geometrical isomers with known compounds in the literature.

22 J. F. Hartwig, Inorg. Chem., 2007, 46, 1936.

23 M. Seki and K. Mori, Eur. J. Org. Chem., 1999, 2965.

24 T. Jeffery-Luong and G. Linstrumelle, Synthesis, 1982, 738.

25 (a) Modern Allene Chemistry, ed. N. Krause and A. S. K. Hashmi, Wiley-VCH, Weinheim, 2004, vol. 1 and 2; (b) For the use of allenyl metal reagents in cross-coupling reactions see: K. Radkowski, G. Seidel and A. Fürstner, Chem. Lett., 2011, 40, 950 and references cited therein.

26 Unfortunately, mixtures of propargyl/1,2-allenyl species were observed when other allenyl lithium reagents or substrates were used (see ESI, Scheme S3†).

27 (a) J. A. Soderquist and G. J.-H. Hsu, Organometallics, 1982, 1, 830; (b) U. Lehmann, S. Awasthi and T. Minehan, Org. Lett., 2003, 5, 2405; (c) S. E. Denmark and L. Neuville, Org. Lett., 2000, 2, 3221.

28 (a) M. Kosugi, T. Sumiya, Y. Obara, M. Suzuki, H. Sano and T. Migita, Bull. Chem. Soc. Jpn., 1987, 60, 767; (b) H. B. Kwon, B. H. McKee and J. K. Stille, J. Org. Chem., 1990, 55, 3114; (c) C. E. Russell and L. S. Hegedus, J. Am. Chem. Soc., 1983, 105, 6943.

$29 \mathrm{H}$. Siegel and M. Eggersdorf, Ketones, Ullmann's Encyclopedia of Industrial Chemistry, Wiley-VCH Verlag GmbH, Germany, 2000, pp. 187-207.

30 S. D. Ramgren and N. K. Garg, Org. Lett., 2014, 16, 824 and references cited therein. 